\title{
Role of Rutin on Nitric Oxide Synthesis in Human Umbilical Vein Endothelial Cells
}

\author{
Azizah Ugusman, ${ }^{1}$ Zaiton Zakaria, ${ }^{1}$ Kien Hui Chua, ${ }^{1}$ \\ Nor Anita Megat Mohd Nordin, ${ }^{1}$ and Zaleha Abdullah Mahdy ${ }^{2}$ \\ ${ }^{1}$ Department of Physiology, Faculty of Medicine, Universiti Kebangsaan Malaysia Medical Centre, Jalan Raja Muda Abdul Aziz, \\ 50300 Kuala Lumpur, Malaysia \\ ${ }^{2}$ Department of Obstetrics and Gynaecology, Universiti Kebangsaan Malaysia Medical Centre, Jalan Yaacob Latif, 56000 Cheras, \\ Kuala Lumpur, Malaysia
}

Correspondence should be addressed to Zaiton Zakaria; zaitonukm@gmail.com

Received 9 April 2014; Accepted 10 June 2014; Published 24 June 2014

Academic Editor: Tullio Florio

Copyright ( 2014 Azizah Ugusman et al. This is an open access article distributed under the Creative Commons Attribution License, which permits unrestricted use, distribution, and reproduction in any medium, provided the original work is properly cited.

Nitric oxide (NO), produced by endothelial nitric oxide synthase (eNOS), is a major antiatherogenic factor in the blood vessel. Oxidative stress plays an important role in the pathogenesis of various cardiovascular diseases, including atherosclerosis. Decreased availability of endothelial NO promotes the progression of endothelial dysfunction and atherosclerosis. Rutin is a flavonoid with multiple cardiovascular protective effects. This study aimed to investigate the effects of rutin on eNOS and NO production in cultured human umbilical vein endothelial cells (HUVEC). HUVEC were divided into four groups: control; oxidative stress induction with $180 \mu \mathrm{M} \mathrm{H}_{2} \mathrm{O}_{2}$; treatment with $300 \mu \mathrm{M}$ rutin; and concomitant induction with rutin and $\mathrm{H}_{2} \mathrm{O}_{2}$ for 24 hours. HUVEC treated with rutin produced higher amount of NO compared to control $(P<0.01)$. In the oxidative stress-induced HUVEC, rutin successfully induced cells' NO production $(P<0.01)$. Rutin promoted NO production in HUVEC by inducing eNOS gene expression $(P<0.05)$, eNOS protein synthesis $(P<0.01)$, and eNOS activity $(P<0.05)$. Treatment with rutin also led to increased gene and protein expression of basic fibroblast growth factor (bFGF) in HUVEC. Therefore, upregulation of eNOS expression by rutin may be mediated by bFGF. The results showed that rutin may improve endothelial function by augmenting NO production in human endothelial cells.

\section{Introduction}

Endothelial nitric oxide (NO) possesses various antiatherosclerotic properties. It is involved in the control of vascular tone and blood pressure by causing vasodilatation. NO also inhibits various steps involved in atherogenesis such as oxidation of low density lipoprotein (LDL), platelet aggregation, leucocytes adhesion, and abnormal proliferation of vascular smooth muscle cells [1]. Loss of normal NO production from the endothelium is a cardinal feature of endothelial dysfunction. Based on the vasculoprotective effects of NO, increased endothelial NO synthesis has the potential to be used as a target in the prevention and treatment of cardiovascular diseases [2].

Endothelial nitric oxide synthase (eNOS) is the major enzyme responsible for $\mathrm{NO}$ production in the blood vessels [3]. NO synthesis increases when the level and activity of eNOS in the endothelial cells increase [4]. NO synthesis can also be modulated through regulation of eNOS gene expression [5]. Growth factors such as transforming growth factor beta-1 (TGF- $\beta 1$ ), vascular endothelial growth factor (VEGF), and basic fibroblast growth factor (bFGF) were reported to upregulate eNOS gene expression [6].

Oxidative stress results from the imbalance between the prooxidative and the antioxidative defense mechanisms of the body. The major source of endogenous reactive oxygen species (ROS) is generated from $\mathrm{H}_{2} \mathrm{O}_{2}$ [7], which has been extensively used to induce oxidative stress in in vitro experiments $[8,9]$. Oxidative stress plays an important role in the pathogenesis of atherosclerosis and cardiovascular diseases by promoting endothelial dysfunction, inflammation, and 
lipid/lipoprotein peroxidation and lowering NO bioavailability [10]. Loss of normal NO production from the endothelium is a cardinal feature of endothelial dysfunction [11].

Flavonoids are a group of phenolic compounds which can be found naturally in plants. Epidemiological studies indicate that increased intake of dietary flavonoids is associated with a decrease in the risk of cardiovascular diseases [12]. The cardiovascular protective effects of flavonoids may be mediated by multiple mechanisms. One possible pathway is by increasing eNOS expression and NO synthesis. Increased NO, produced by higher levels of eNOS, might in turn inhibit pathways leading to endothelial dysfunction and atherosclerosis [13].

Rutin $\left(3,3^{\prime}, 4^{\prime}, 5,7\right.$-pentahydroxyflavone-3-rhamnoglucoside) is a flavonoid which can be found in buckwheat, apple, green tea, Betula pendula leaves, and other sources $[14,15]$. It has antioxidant [16], anti-inflammatory [17], and antiplatelet [18] activities. Rutin supplementation causes lowering of blood pressure in rats with metabolic syndrome [19] and relaxation of rats' aortic rings [20].

Rutin is one of the active compounds found in Piper sarmentosum leaves [15]. Piper sarmentosum is a creeping terrestrial herbaceous plant that belongs to the Piperaceae family. It is commonly found in the tropical and subtropical regions of the world, such as the Asian and South East Asia regions [21]. Piper sarmentosum had been shown to promote NO production in HUVEC [22]. However, the active compound responsible for the effect remains unclear. Therefore, the present study was designed to look into the effects of rutin on the eNOS system and NO synthesis in HUVEC. The results of the present study may help in the prevention and treatment of endothelial dysfunction which is linked to various cardiovascular diseases. Furthermore, beneficial results from this study will also add to the scientific basis of using Piper sarmentosum as a supplement for cardiovascular health.

\section{Materials and Methods}

2.1. Materials. Rutin (purity 95\%), hydrogen peroxide $\left(\mathrm{H}_{2} \mathrm{O}_{2}\right)$, and ethidium bromide were purchased from Sigma (St. Louis, USA). Collagenase type I was purchased from GibcoInvitrogen Corp. (Grand Island, USA). Medium 200 and low serum growth supplement (LSGS) were purchased from Cascade Biologics (Grand Island, USA). TRI Reagent and polyacryl carrier were purchased from Molecular Research Center (Cincinnati, USA). RNase and DNase free water and SuperScript III First-Strand Synthesis SuperMix were purchased from Invitrogen (Carlsbad, USA). IQ SYBR Green Supermix was purchased from Bio-Rad (Hercules, USA). Quantikine human eNOS ELISA kit was purchased from R\&D Systems Inc. (Minneapolis, USA). Calbiochem nitric oxide synthase assay kit was purchased from EMD Chemicals (Darmstadt, Germany). Bioxytech nitric oxide assay kit was purchased from OxisResearch (Portland, USA). Procarta cytokine kit was purchased from Panomics (Fremont, USA).

2.2. Cell Culture and Treatment Protocol. Human umbilical cords were obtained under sterile condition from labour room in Hospital Kuala Lumpur. Written consent was obtained from each subject and the present study was approved by the Ethical Research Committee of Universiti Kebangsaan Malaysia Medical Center (approval code: FF-092-2010). HUVEC were obtained from umbilical cord veins by $0.1 \%$ collagenase type I digestion. Cells were grown in medium 200 supplemented with LSGS at $37^{\circ} \mathrm{C}$ in a humidified atmosphere of $5 \% \mathrm{CO}_{2}$ and $95 \%$ air. HUVEC were confirmed by the typical endothelial cell cobblestone morphology and the positive expressions of von Willebrand factor and CD31 in immunocytochemistry. The culture medium was changed every other day until the cells reached confluence. HUVEC from passage 3 at $80 \%$ confluency were used for experiments. The cells were divided into four groups as follows: control; oxidative stress induction with $180 \mu \mathrm{M} \mathrm{H}_{2} \mathrm{O}_{2}$; treatment with $300 \mu \mathrm{M}$ rutin only; and concomitant induction with $300 \mu \mathrm{M}$ rutin and $180 \mu \mathrm{M} \mathrm{H}_{2} \mathrm{O}_{2}$. All treatments were given for 24 hours. The dose of $\mathrm{H}_{2} \mathrm{O}_{2}$ used was based on the $\mathrm{IC}_{50}$ of $\mathrm{H}_{2} \mathrm{O}_{2}$ adopted from a previous study [22] while $300 \mu \mathrm{M}$ rutin was used as it significantly increased HUVEC viability by almost 50 percent when induced with $180 \mu \mathrm{M} \mathrm{H}_{2} \mathrm{O}_{2}$ [15].

\subsection{Quantitative Reverse Transcription Polymerase Chain} Reaction (qPCR) for Analysis of eNOS, TGF $\beta 1, b F G F$, and VEGF mRNA Expression. Following treatment for 24 hours, total ribonucleic acid (RNA) from HUVEC was extracted using TRI Reagent as previous research protocol [23]. Polyacryl carrier was added to precipitate the total RNA. Extracted RNA pellet was then washed with $75 \%$ ethanol and dried prior to dissolving it in RNase and DNase free water. Extracted total RNA was assessed for its purity and quantity using Nanodrop ND-100 spectrophotometer (Wilmington DE, USA) and stored at $-80^{\circ} \mathrm{C}$ before use. Complimentary DNA (cDNA) was synthesized using SuperScript III FirstStrand Synthesis SuperMix. A total of $20 \mu \mathrm{L}$ of volume reaction which consisted of $10 \mu \mathrm{L}$ of $2 \mathrm{X}$ RT reaction mix, $2 \mu \mathrm{L}$ of RT enzyme, $5 \mu \mathrm{L}$ of total RNA, and $3 \mu \mathrm{L}$ of DEPCtreated water was incubated at $25^{\circ} \mathrm{C}$ for 10 minutes for primer annealing then at $50^{\circ} \mathrm{C}$ for 30 minutes for reverse transcription. Following this, the reaction was terminated at $85^{\circ} \mathrm{C}$ for 5 minutes, chilled on ice for 1 minute, and $1 \mu \mathrm{L}$ of $E$. coli RNase $\mathrm{H}$ was added to the mixture. The cDNA was further incubated at $37^{\circ} \mathrm{C}$ for 20 minutes and stored at $-20^{\circ} \mathrm{C}$ until use. Subsequently, qPCR was carried out to determine the mRNA expression level of eNOS, TGF $\beta 1$, bFGF, and VEGF. Glycerylaldehyde-3-phosphate dehydrogenase $(\mathrm{GAPDH})$ was used as the reference gene. Primer 3 software was used to design the primers from NIH GenBank database. The primer sequences for eNOS, TGF $\beta 1$, bFGF, and VEGF were listed in Table 1 . The qPCR reaction was performed with $1 \mu \mathrm{L}$ of cDNA, $5 \mu \mathrm{M}$ of each forward and reverse primer and $12.5 \mu \mathrm{L}$ of IQ SYBR Green Supermix in BioRad iCycler (Bio-Rad, USA) with reaction profile of: 40 cycles of $95^{\circ} \mathrm{C}$ (10 seconds) and $61^{\circ} \mathrm{C}$ (30 seconds). The reaction kinetic of each primer set and protocol was verified with melting profile and product size was further confirmed with $2 \%$ agarose gel electrophoresis stained with ethidium bromide. The threshold cycle (CT) value was determined 
TABLE 1: List of primers for qPCR analysis.

\begin{tabular}{|c|c|c|c|}
\hline mRNA target & Genbank accession number & Primer sequence & PCR product size (bp) \\
\hline GAPDH & NM_002046 & $\begin{array}{l}\text { F: tcc ctg agc tga acg gga ag } \\
\text { R: gga gga gtg ggt gtc gct gt }\end{array}$ & 217 \\
\hline eNOS & NM_000603 & $\begin{array}{l}\text { F: ttt gec ctt atg gat gtg aag } \\
\text { R: cgc atc aaa gaa agc tca gtc }\end{array}$ & 139 \\
\hline TGF $\beta 1$ & NM_000358 & $\begin{array}{l}\text { F: aac aca tca gag ctc cga gaa } \\
\text { R: gag gta tcg cca gga att gtt }\end{array}$ & 141 \\
\hline VEGF & NM_001033756 & $\begin{array}{l}\text { F: ccc act gag gag tcc aac at } \\
\text { R: aaa tgc ttt ctc cgc tct ga }\end{array}$ & 173 \\
\hline bFGF & NM_002006 & $\begin{array}{l}\text { F: ccg tta cct ggc tat gaa gg } \\
\text { R: act gcc cag ttc gtt tca gt }\end{array}$ & 158 \\
\hline
\end{tabular}

and the relative mRNA expression of eNOS, TGF $\beta 1$, bFGF, and VEGF was calculated as follows: $2^{\Delta \Delta \mathrm{CT}}$ with $\Delta \Delta \mathrm{CT}=$ CT GAPDH - CT gene of interest.

\subsection{Enzyme-Linked Immunosorbent Assay (ELISA) for eNOS} Protein Analyses. eNOS protein level of the cultured HUVEC was determined by using Quantikine human eNOS ELISA kit. HUVEC were washed with phosphate-buffered saline (PBS) twice, manually scraped from the culture flask, and lysed with $400 \mu \mathrm{L}$ of lysis buffer. The assay was performed using $100 \mu \mathrm{L}$ of the cell lysate. The cell lysate was pipetted into the 96-well plate so that any eNOS present would be bound to the immobilized antibody in the plate. After washing away any unbound substances, eNOS conjugate was added to the wells. This was followed by addition of substrate solution and stop solution. The optical density of each well was determined at $450 \mathrm{~nm}$ using an ELISA microplate reader.

2.5. Determination of eNOS Activity. eNOS activity was determined by using Calbiochem nitric oxide synthase assay kit. The principle of this assay was based on the measurement of nitrite produced by eNOS in the sample in a timed reaction. HUVEC were scraped from the culture flask, homogenized in PBS, and centrifuged at 10,000 g for 20 minutes. Then, the cell lysate in the supernatant solution was filtered through a $0.45 \mu \mathrm{m}$ filter prior to ultracentrifugation at $100,000 \mathrm{~g}$ for 15 minutes. A total of $40 \mu \mathrm{L}$ of the cell lysate was diluted with $20 \mu \mathrm{L}$ of assay buffer. Then the samples were mixed with NADPH, nitrate reductase, cofactor preparation solution, and lactate dehydrogenase (LDH). Total nitrite was measured at $540 \mathrm{~nm}$ absorbance by reaction with Griess reagents (sulfanilamide and naphthalene-ethylenediamine dihydrochloride). Concentration of nitrite in the sample was calculated using a standard curve. The eNOS activity was expressed as nmol of nitrite/min per $\mathrm{mL}$ of sample.

\subsection{Determination of Endothelial Nitric Oxide Production.} Production of NO by HUVEC was measured as its stable oxidation product; nitrite, using Bioxytech nitric oxide assay kit. Briefly, $50 \mu \mathrm{L}$ of the culture medium was diluted with $35 \mu \mathrm{L}$ assay buffer and mixed with $10 \mu \mathrm{L}$ nitrate reductase and $10 \mu \mathrm{L}$ NADH. Following 20 minutes of incubation to convert nitrate to nitrite, total nitrite was measured at $540 \mathrm{~nm}$ absorbance by reaction with Griess reagents (sulfanilamide and naphthalene-ethylenediamine dihydrochloride).

2.7. Luminex Assay for TGF 1, bFGF, and VEGF Protein Analyses. TGF $\beta 1, \mathrm{bFGF}$, and VEGF protein levels of the cultured HUVEC were obtained using Procarta cytokine kit in 96-well plate ELISA-based formats according to manufacturer's instructions. The sensitivity of the assay (limit of detection) was $1 \mathrm{pg} / \mathrm{mL} /$ cytokine [24]. Following incubation with antibody-conjugated beads, detection antibodies, and streptavidin-phycoerythrin (SA-PE) complexes, samples were analyzed with Luminex 100 instrument (Luminex Corporation). Fluorescence signals were collected and data was expressed in $\mathrm{pg} / \mathrm{mL}$ using internal standards as the mean of three individual experiments done in triplicate.

2.8. Statistical Analysis. Data was tested for normality using Kolmogorov-Smirnov test and all variables were normally distributed. Data was expressed as mean \pm SEM. Statistical analysis between two groups was performed using paired Student's $t$-test using SPSS version 17.0 software. Values of $P<0.05$ were considered statistically significant.

\section{Results}

3.1. Effect of Rutin on eNOS mRNA Expression in HUVEC. eNOS mRNA expression in HUVEC treated with rutin increased by 2.1-fold compared to the control group $(P<$ 0.05) (Figure 1). In the oxidative stress-induced group, HUVEC treated with $\mathrm{H}_{2} \mathrm{O}_{2}$ showed a significant increase in eNOS mRNA expression by 1.6 times compared to the control group $(P<0.05)$. Concomitant treatment of HUVEC with both rutin and $\mathrm{H}_{2} \mathrm{O}_{2}$ caused an increase in eNOS mRNA expression by 1.8 times compared to the control group $(P<$ 0.05).

3.2. Effect of Rutin on eNOS Protein Level in HUVEC. eNOS protein level in HUVEC treated with rutin $(1.864 \pm 0.088 \times$ $\left.10^{3} \mathrm{pg} / \mathrm{mL}\right)$ increased significantly $(P<0.01)$ compared to the control $\left(1.441 \pm 0.113 \times 10^{3} \mathrm{pg} / \mathrm{mL}\right.$ ) (Figure 2). The $\mathrm{H}_{2} \mathrm{O}_{2}$ induced group $\left(1.771 \pm 0.075 \times 10^{3} \mathrm{pg} / \mathrm{mL}\right)$ also showed a significant increase in eNOS protein level compared to the control $(P<0.05)$. HUVEC induced with both rutin 


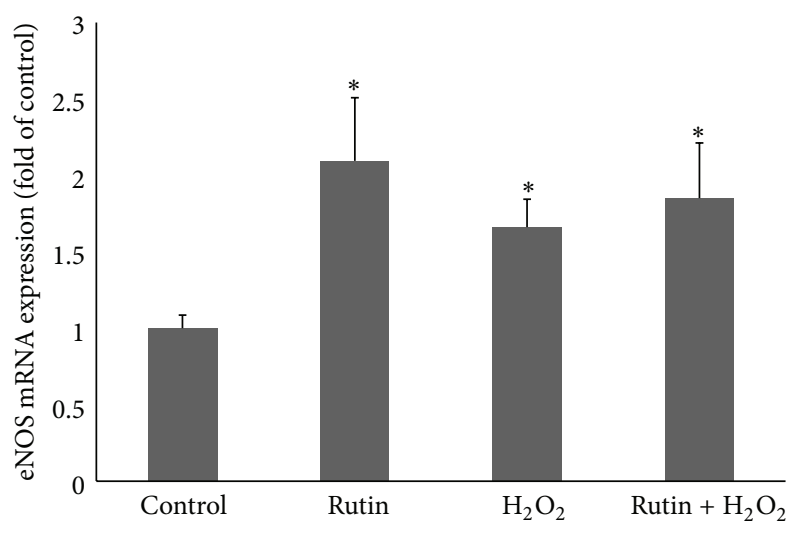

FIgURE 1: Bar chart showing eNOS mRNA expression in control, rutin, $\mathrm{H}_{2} \mathrm{O}_{2}$, and rutin $+\mathrm{H}_{2} \mathrm{O}_{2}$ groups. Values are expressed as means \pm SEM of $n=8 .{ }^{*} P<0.05$ versus control.

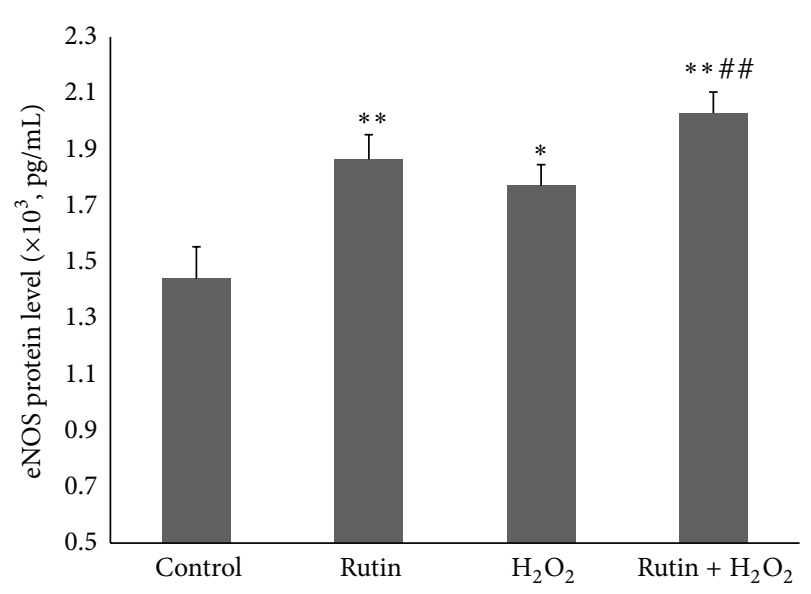

FIGURE 2: Bar chart showing eNOS protein level in control, rutin, $\mathrm{H}_{2} \mathrm{O}_{2}$, and rutin $+\mathrm{H}_{2} \mathrm{O}_{2}$ groups. Values are expressed as means \pm SEM of $n=8$. ${ }^{*} P<0.05$ versus control; ${ }^{* *} P<0.01$ versus control; and ${ }^{\# \#} P<0.01$ versus $\mathrm{H}_{2} \mathrm{O}_{2}$.

and $\mathrm{H}_{2} \mathrm{O}_{2}\left(2.029 \pm 0.075 \times 10^{3} \mathrm{pg} / \mathrm{mL}\right)$ showed a significant increase in eNOS protein level compared to the control group $(P<0.01)$ and $\mathrm{H}_{2} \mathrm{O}_{2}$ group $(P<0.01)$.

3.3. Effect of Rutin on eNOS Activity in HUVEC. eNOS activity in HUVEC treated with rutin $\left(4.823 \pm 0.205 \times 10^{-2}\right.$ nmoles/ $\mathrm{mL} / \mathrm{min})$ increased significantly $(P<0.05)$ compared to the control $\left(4.304 \pm 0.065 \times 10^{-2} \mathrm{nmoles} / \mathrm{mL} / \mathrm{min}\right)$ (Figure 3$)$. The $\mathrm{H}_{2} \mathrm{O}_{2}$-induced group $\left(4.573 \pm 0.118 \times 10^{-2} \mathrm{nmoles} / \mathrm{mL} /\right.$ $\mathrm{min})$ also showed a significant increase in eNOS activity compared to the control $(P<0.05)$. HUVEC induced with both rutin and $\mathrm{H}_{2} \mathrm{O}_{2}\left(4.986 \pm 0.074 \times 10^{-2} \mathrm{nmoles} / \mathrm{mL} / \mathrm{min}\right)$ showed a significant increase in eNOS activity compared to the control group $(P<0.01)$ and the $\mathrm{H}_{2} \mathrm{O}_{2}$ group $(P<0.01)$.

3.4. Effect of Rutin on NO Production in HUVEC. There was a significant increase $(P<0.01)$ in the level of NO produced by HUVEC treated with rutin $(4.095 \pm 0.203 \mu \mathrm{M})$ compared

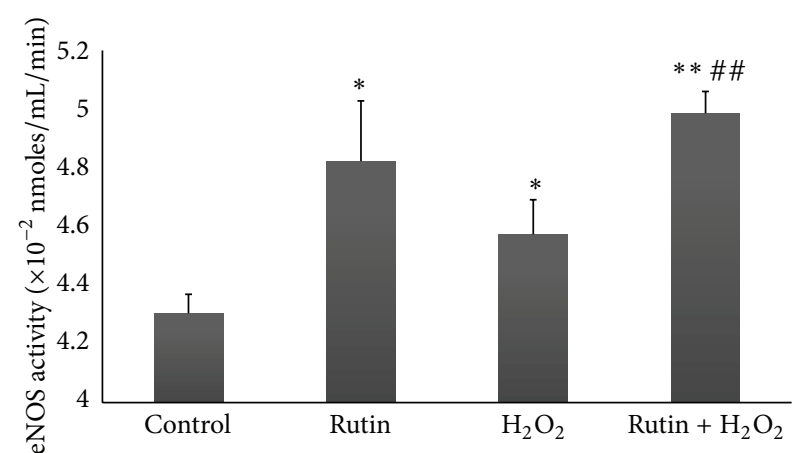

FIGURE 3: Bar chart showing eNOS activity in control, rutin, $\mathrm{H}_{2} \mathrm{O}_{2}$, and rutin $+\mathrm{H}_{2} \mathrm{O}_{2}$ groups. Values are expressed as means \pm SEM of $n=8 .{ }^{*} P<0.05$ versus control; ${ }^{* *} P<0.01$ versus control; and ${ }^{\# \#} P<0.01$ versus $\mathrm{H}_{2} \mathrm{O}_{2}$.

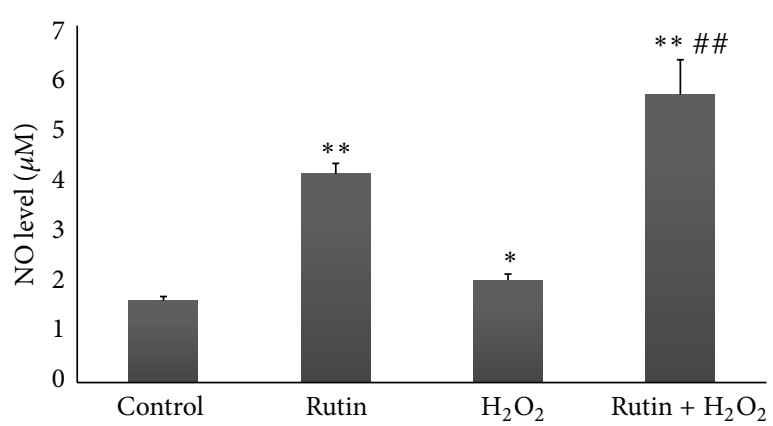

FIgUre 4: Bar chart showing NO level in control, rutin, $\mathrm{H}_{2} \mathrm{O}_{2}$, and rutin $+\mathrm{H}_{2} \mathrm{O}_{2}$ groups. Values are expressed as means \pm SEM of $n=8$. ${ }^{*} P<0.05$ versus control; ${ }^{* *} P<0.01$ versus control; and ${ }^{\# \#} P<0.01$ versus $\mathrm{H}_{2} \mathrm{O}_{2}$.

to the control $(1.605 \pm 0.08 \mu \mathrm{M})$ (Figure 4$)$. HUVEC induced with $\mathrm{H}_{2} \mathrm{O}_{2}$ produced higher amount of $\mathrm{NO}(2.01 \pm 0.115 \mu \mathrm{M})$ compared to the control $(P<0.01)$. The highest level of NO was produced by HUVEC treated with both rutin and $\mathrm{H}_{2} \mathrm{O}_{2}(5.65 \pm 0.683 \mu \mathrm{M})$ whereby this increase was significant compared to the control group $(P<0.01)$ and the $\mathrm{H}_{2} \mathrm{O}_{2}$ group $(P<0.01)$.

3.5. Effects of Rutin on TGF $\beta 1, b F G F$, and VEGF $m R N A$ Expression in HUVEC. bFGF mRNA expression in HUVEC treated with rutin increased significantly $(P<0.05)$ by 1.6 times compared to the control (Figure 5). HUVEC treated with both rutin and $\mathrm{H}_{2} \mathrm{O}_{2}$ also showed higher level of bFGF mRNA expression compared to the control $(P<0.01)$ and the $\mathrm{H}_{2} \mathrm{O}_{2}(P<0.01)$ groups. There was no significant difference in the mRNA expression of TGF $\beta 1$ and VEGF.

3.6. Effects of Rutin on TGF $\beta 1, b F G F$, and VEGF Protein Level in HUVEC. bFGF protein level in HUVEC treated with rutin $(1169.715 \pm 34.663 \mathrm{pg} / \mathrm{mL})$ increased significantly $(P<0.01)$ compared to the control $(946.198 \pm 44.043 \mathrm{pg} /$ $\mathrm{mL}$ ) (Figure 6). HUVEC treated with both rutin and $\mathrm{H}_{2} \mathrm{O}_{2}$ also showed higher level of bFGF protein compared to the control $(P<0.05)$ and $\mathrm{H}_{2} \mathrm{O}_{2}(947.696 \pm 48.933 \mathrm{pg} / \mathrm{mL})$ 


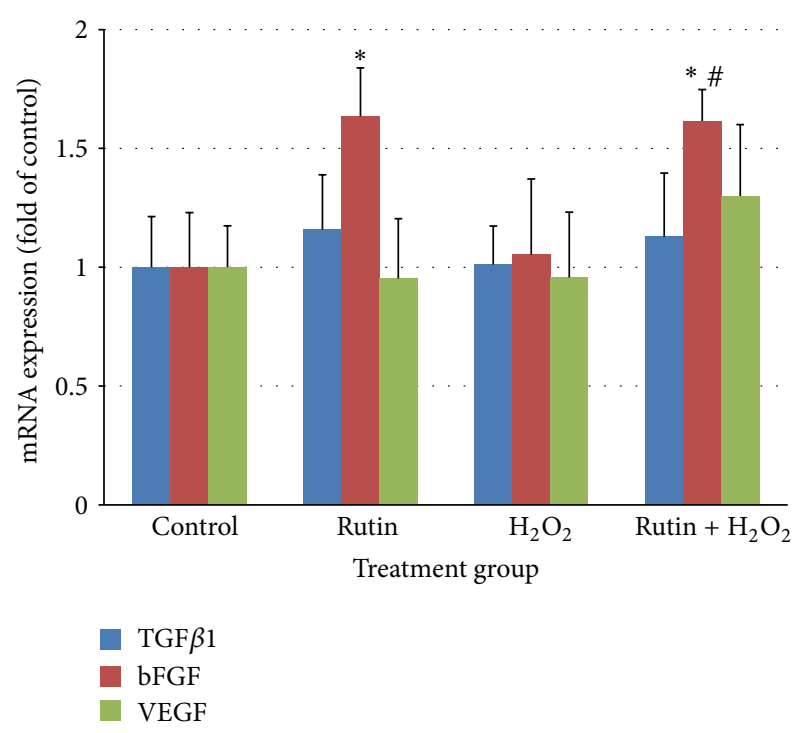

Figure 5: Bar chart showing TGF $\beta 1$, bFGF, and VEGF mRNA expression in control, rutin, $\mathrm{H}_{2} \mathrm{O}_{2}$, and rutin $+\mathrm{H}_{2} \mathrm{O}_{2}$ groups. Values are expressed as means \pm SEM of $n=8 .{ }^{*} P<0.05$ versus control; ${ }^{\#} \mathrm{P}<0.05$ versus $\mathrm{H}_{2} \mathrm{O}_{2}$.

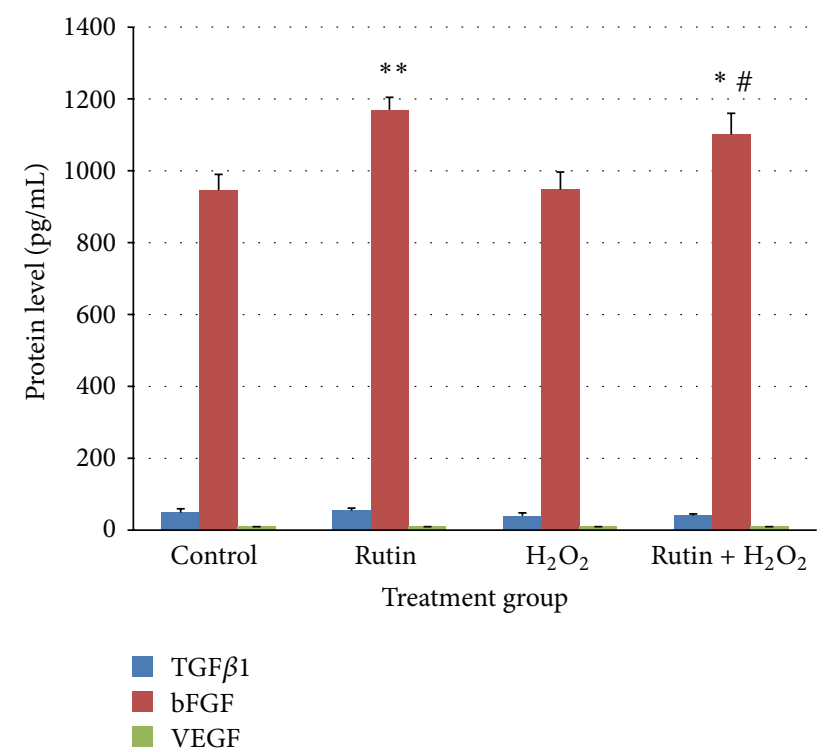

FIGURE 6: Bar chart showing TGF $\beta 1$, bFGF, and VEGF protein level in control, rutin, $\mathrm{H}_{2} \mathrm{O}_{2}$, and rutin $+\mathrm{H}_{2} \mathrm{O}_{2}$ groups. Values are expressed as means \pm SEM of $n=8 .{ }^{*} P<0.05$ versus control; ${ }^{* *} P<0.01$ versus control; and ${ }^{*} P<0.05$ versus $\mathrm{H}_{2} \mathrm{O}_{2}$.

$(P<0.05)$ groups. There was no significant difference in the protein level of TGF $\beta 1$ and VEGF. The increase in bFGF protein level was in parallel with the increase in bFGF mRNA expression (Figure 5).

\section{Discussion}

Results showed that rutin increased NO production by HUVEC. Rutin also caused upregulation of eNOS mRNA expression and increase in eNOS protein level and eNOS activity. The increase in eNOS mRNA expression caused more eNOS protein to be synthesized. The higher amount of eNOS protein led to a higher level of eNOS activity. This resulted in an increase in the NO production by HUVEC. eNOS protein level was significantly increased in the combined rutin $+\mathrm{H}_{2} \mathrm{O}_{2}$ group compared to the $\mathrm{H}_{2} \mathrm{O}_{2}$ group $(P<$ 0.01) (Figure 2). However, eNOS mRNA expression was not significantly increased when comparing between these two groups (Figure 1). This could be due to the level of eNOS protein in the rutin $+\mathrm{H}_{2} \mathrm{O}_{2}$ group which was high enough to inhibit eNOS mRNA expression via negative feedback mechanism [25].

Even though $\mathrm{H}_{2} \mathrm{O}_{2}$ treatment alone increased NO production, the combined treatment of HUVEC with rutin and $\mathrm{H}_{2} \mathrm{O}_{2}$ significantly increased $\mathrm{NO}$ production compared to both control and $\mathrm{H}_{2} \mathrm{O}_{2}$ groups. The results suggested that rutin may improve endothelial function by augmenting NO production in human endothelial cells. Piper sarmentosum was reported to enhance endothelial NO synthesis [22]. Since rutin is one of the major flavonoids found in Piper sarmentosum [15], it may play a role in modulating the stimulatory effect of Piper sarmentosum on NO production.

An earlier study reported rutin to cause vasorelaxation in potassium- and phenylephrine-induced contractions in isolated rat thoracic aorta [20]. The vasorelaxant effect of rutin involved the release of $\mathrm{NO}$ from the endothelium as pretreatment with NO synthase inhibitor, and NG-nitro-Larginine methyl ester (L-NAME) attenuated the response [20]. Rutin-treated rats with metabolic syndrome had lower blood pressure and improved endothelial function. The hypotensive effect of rutin could be mediated by the increase in NO [19].

Oxidative stress can contribute to the development and progression of atherosclerosis by promoting endothelial dysfunction, inflammation, and lipid peroxidation and lowering NO bioavailability [10]. In the present study, oxidative stress induction in HUVEC by addition of $180 \mu \mathrm{M} \mathrm{H}_{2} \mathrm{O}_{2}$ increased eNOS mRNA expression, eNOS protein level eNOS activity, and $\mathrm{NO}$ level (Figures 1, 2, 3, and 4). The responses to $\mathrm{H}_{2} \mathrm{O}_{2}$ in this study were in accordance with earlier reports $[10,26]$. $\mathrm{NO}$ level was higher in the $\mathrm{H}_{2} \mathrm{O}_{2}$-treated group compared to the control group. This may be due to induction of $\mathrm{NO}$ production by $\mathrm{H}_{2} \mathrm{O}_{2}$ as part of the self-protective mechanism of the cells. The dose of $\mathrm{H}_{2} \mathrm{O}_{2}$ used in this study was not lethal to HUVEC, therefore the cells were still able to increase its endogenous $\mathrm{NO}$ production when being challenged by $\mathrm{H}_{2} \mathrm{O}_{2}$. However, $\mathrm{H}_{2} \mathrm{O}_{2}$ also caused oxidative destruction of the synthesized $\mathrm{NO}$, which explained why the increase in $\mathrm{NO}$ in the $\mathrm{H}_{2} \mathrm{O}_{2}$-treated group was not as high as the other groups like rutin and the combined rutin and $\mathrm{H}_{2} \mathrm{O}_{2}$ groups (Figure 4). $\mathrm{H}_{2} \mathrm{O}_{2}$-upregulated eNOS expression represents a self-protective mechanism of the endothelial cells to maintain NO bioactivity under conditions of enhanced oxidative stress. $\mathrm{H}_{2} \mathrm{O}_{2}$ also increases eNOS activity by inducing changes in the phosphorylation status of the enzyme [27].

Antioxidants are well known to enhance the biological actions of NO by protecting NO against oxidative destruction by ROS [27]. Rutin was shown to exhibit antioxidant 


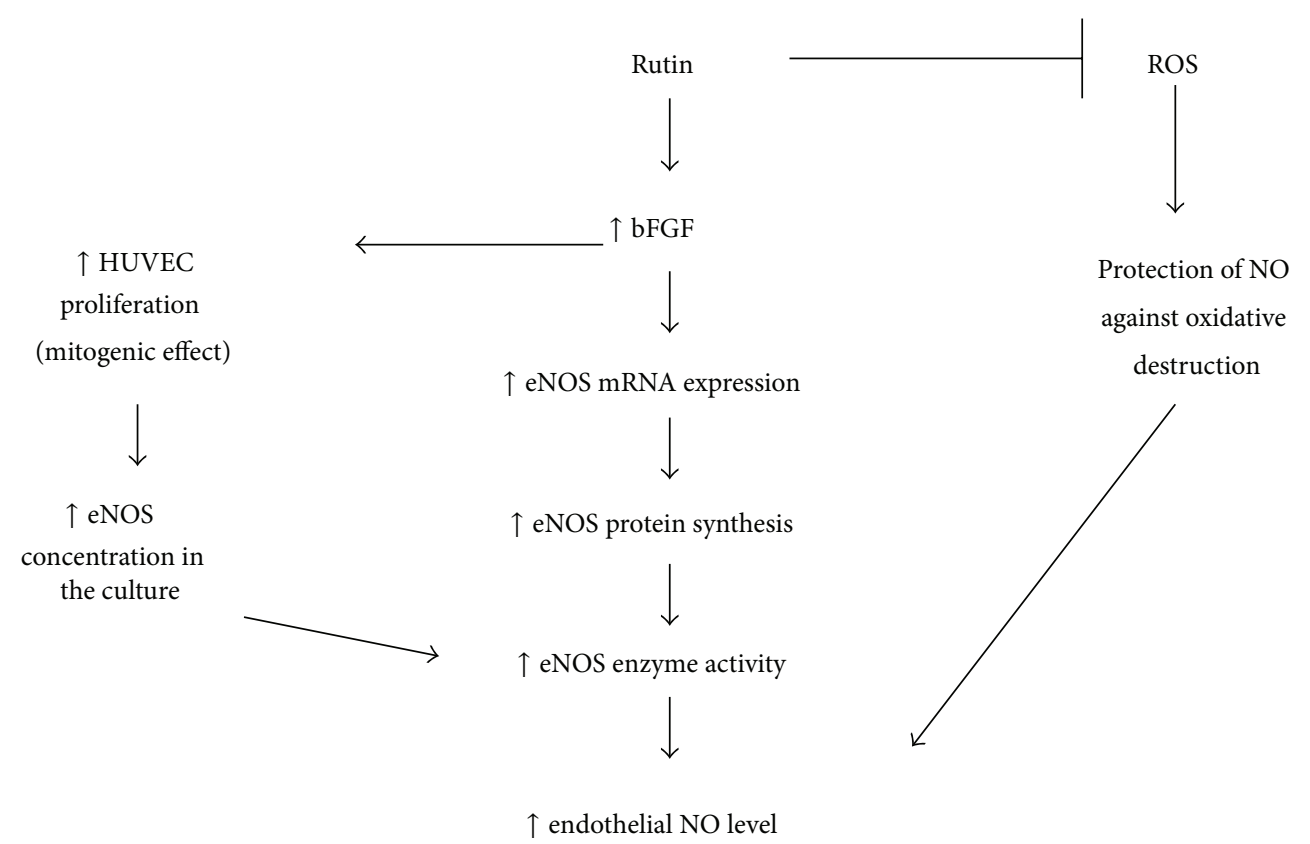

FIGURE 7: Schematic representation of mechanisms involved in rutin-mediated NO synthesis in HUVEC.

properties [16] and cytoprotective effects against $\mathrm{H}_{2} \mathrm{O}_{2}$ induced oxidative cell damage [15]. Thus, rutin may directly protect $\mathrm{NO}$ from oxidative destruction by $\mathrm{H}_{2} \mathrm{O}_{2}$. Rutin also enhanced NO production in HUVEC through increase in eNOS mRNA expression and protein synthesis as well as the enzyme activity (Figures 1, 2, and 3). Thus, all these mechanisms contributed to the increase in the NO level.

In a previous study, rutin significantly attenuated $\mathrm{H}_{2} \mathrm{O}_{2}$-induced cytotoxicity and apoptosis in HUVEC in a concentration-dependant manner [28]. Reactive oxygen species (ROS) (superoxide, $\mathrm{H}_{2} \mathrm{O}_{2}$, and hydroxyl radicals) are potent intracellular oxidants which were proposed as critical regulators of apoptosis [29]. Reduced glutathione (GSH) is a major antioxidant that protects cells from oxidative stress by scavenging peroxides in the mitochondria [30]. $\mathrm{H}_{2} \mathrm{O}_{2}$ may cause endothelial cell injury by inducing mitochondrial dysfunction which includes loss of mitochondrial membrane potential [31]. Rutin protected $\mathrm{HUVEC}$ against $\mathrm{H}_{2} \mathrm{O}_{2}$ induced cytotoxicity by decreasing the intracellular ROS level, increasing the intracellular GSH, and restoring the mitochondrial membrane potential, along with the capacity of suppressing endothelial cell apoptosis [28].

Incubation of HUVEC with 50, 100, and $200 \mu \mathrm{M} \mathrm{H}_{2} \mathrm{O}_{2}$ for one hour was able to stimulate inducible nitric oxide synthase (iNOS) mRNA and protein [32]. Therefore, the $\mathrm{NO}$ produced by the $\mathrm{H}_{2} \mathrm{O}_{2}$-treated group may be also contributed to iNOS apart from eNOS (Figure 4). Previous study showed that rutin suppressed iNOS gene transcription and NO production in lipopolysaccharide-stimulated RAW 264.7 macrophages [33]. Rutin also inhibited iNOS activity in the kidneys of rats during ischemia-reperfusion injury [34].

Results of the present study also showed that rutin increased bFGF mRNA and protein expression (Figures 5 and $6)$. There were no significant changes in mRNA and protein expression of TGF $\beta 1$ and VEGF. Previous studies showed that bFGF caused an increase in the eNOS expression in vitro and in vivo [35]. Since rutin increased the expression of eNOS and bFGF, it is suggested that upregulation of eNOS expression by rutin may be mediated by bFGF. However, in the present study, the data was not enough to conclude the role of TGF $\beta 1$, VEGF, and bFGF in rutin-induced eNOS expression and NO production. We advocate parallel experiments using specific inhibitor or siRNA in future.

Incubation of bovine aortic endothelial cells with bFGF leads to increased eNOS mRNA expression, eNOS protein level, and eNOS activity [36]. Besides, bFGF also stimulated the expression of eNOS mRNA and protein in ovine fetoplacental artery endothelial cells [37]. Intravenously administered bFGF lowered blood pressure by causing systemic vasodilatation [38]. bFGF-induced vasodilatation was attenuated by coadministration of L-NAME; showing that the vasodilatation was mediated by $\mathrm{NO}$-dependent mechanism [39]. Blood vessels of spontaneously hypertensive rats had low bFGF content [40]. Restoration of bFGF to physiological levels either by systemic administration or by in vivo gene transfer significantly augmented the number of endothelial cells with positive immunostaining for eNOS, corrected hypertension, and improved vasorelaxation [40].

bFGF has a mitogenic effect whereby it may stimulate proliferation of various cells including endothelial cells [41]. Rutin stimulated bFGF expression and bFGF had a mitogenic effect on endothelial cells. This mitogenic effect may lead to the increase in HUVEC culture proliferation. Increase in the number of endothelial cells will cause higher concentration of eNOS in the culture. This may lead to increase in eNOS activity and subsequently more NO production by HUVEC. The mechanisms involved in rutin-promoting effects on endothelial NO production were summarized in Figure 7. 
bFGF stimulates eNOS expression via activation of the mitogen-activated protein kinase (MAPK) p44 and p42 pathways or also known as extracellular signal-regulated kinases 1/2 (ERK or ERKs). Active ERK phosphorylates several cytosolic and membrane-bound targets and, upon translocation from the cytoplasm into the nucleus, activates different transcription factors thus also regulating gene transcription [42]. The response to bFGF started when bFGF binds to its receptor which contains tyrosine kinase domain. This may lead to phosphorylation and activation of MAPK p44 and p42 by MAPK kinase in the cytosol. MAPK p44 and p42 will then be translocated from cytosol to nucleus where it stimulates eNOS transcription [37, 43-45]. This activation was inhibited by PD 98059, a specific MAPK kinase inhibitor [37]. Since, rutin increases bFGF which, in turn, increases ERK activity, it may be postulated that rutin may also change ERK kinetic and its intracellular localization between the cytosol and the nucleus.

However, activation of eNOS in Chinese hamster ovary ( $\mathrm{CHO})-\mathrm{K} 1$ cells is independent of the MAPK cascade [46]. In its inactive form, eNOS is bound to caveolin 1 in caveolae at the plasma membrane. Dissociation of eNOS from caveolin 1 and its translocation to the cytosol are important steps in eNOS activation [47]. In CHO-K1 cells, bFGF activates sphingomyelinase to synthesize ceramide, which, in turn, allows the dissociation of eNOS from caveolin 1 and its translocation to cytosol where it catalyzes the synthesis of NO [46].

The results also showed that there was no significant increase in the VEGF $\mathrm{mRNA}$ and protein expression in response to $\mathrm{H}_{2} \mathrm{O}_{2}$ treatment (Figures 5 and 6). However, previous study showed dose-dependent increase in the expression of VEGF in HUVEC treated with 6.25-50 $\mu \mathrm{M} \mathrm{H}_{2} \mathrm{O}_{2}$ [48]. Experimental results obtained with different HUVEC isolates cannot easily be compared to each other because of their different donor origin [49]. Watson et al. [50] reported, for example, that the response to interleukin- 8 stimulation is different among several commercially available HUVEC and "home-isolated" primary cultured HUVEC. Different growth media and growth conditions may also contribute to the variations [50].

\section{Conclusion}

The results of the present study showed that rutin promoted NO production in HUVEC by inducing eNOS mRNA expression, protein synthesis, and eNOS activity. Rutin's stimulatory effect on eNOS expression may be mediated by bFGF.

\section{Conflict of Interests}

The authors declare that they have no conflict of interests.

\section{Acknowledgments}

This work was supported by Research Grants from Universiti Kebangsaan Malaysia Medical Centre (FF-092-2010) and Ministry of Higher Education Malaysia (UKM-FF-03FRGS0037-2010). The authors would like to thank Dr. Thuan
D. Bui from i-DNA Biotechnology Pte Ltd for his technical assistance in running the Luminex assay, Professor Dr. Srijit Das for his assistance in editing the paper, and the staff nurses in labour room, Hospital Kuala Lumpur for their assistance in umbilical cord collections.

\section{References}

[1] K. M. Naseem, "The role of nitric oxide in cardiovascular diseases," Molecular Aspects of Medicine, vol. 26, no. 1-2, pp. 33-65, 2005.

[2] L. J. Ignarro and C. Napoli, "Novel features of nitric oxide, endothelial nitric oxide synthase, and atherosclerosis," Current Atherosclerosis Reports, vol. 6, no. 4, pp. 281-287, 2004.

[3] U. Förstermann and T. Münzel, "Endothelial nitric oxide synthase in vascular disease: From marvel to menace," Circulation, vol. 113, no. 13, pp. 1708-1714, 2006.

[4] K. Steinkamp-Fenske, L. Bollinger, N. Völler et al., "Ursolic acid from the Chinese herb Danshen (Salvia miltiorrhiza L.) upregulates eNOS and downregulates Nox4 expression in human endothelial cells," Atherosclerosis, vol. 195, no. 1, pp. e104-e111, 2007.

[5] H. Li, T. Wallerath, T. Münzel, and U. Förstermann, "Regulation of endothelial-type NO synthase expression in pathophysiology and in response to drugs," Nitric Oxide-Biology and Chemistry, vol. 7, no. 3, pp. 149-164, 2002.

[6] S. C. Tai, G. B. Robb, and P. A. Marsden, "Endothelial nitric oxide synthase: a new paradigm for gene regulation in the injured blood vessel," Arteriosclerosis, Thrombosis, and Vascular Biology, vol. 24, no. 3, pp. 405-412, 2004.

[7] H. Nohl, A. V. Kozlov, L. Gille, and K. Staniek, "Cell respiration and formation of reactive oxygen species: facts and artefacts," Biochemical Society Transactions, vol. 31, no. 6, pp. 1308-1311, 2003.

[8] X. Q. Xiao, N. T. Lee, P. R. Carlier, Y. Pang, and Y. F. Han, "Bis(7)tacrine, a promising anti-Alzheimer's agent, reduces hydrogen peroxide-induced injury in rat pheochromocytoma cells: comparison with tacrine," Neuroscience Letters, vol. 290, no. 3, pp. 197-200, 2000.

[9] B. Yang, T. N. Oo, and V. Rizzo, "Lipid rafts mediate $\mathrm{H}_{2} \mathrm{O}_{2}$ prosurvival effects in cultured endothelial cells," The FASEB Journal, vol. 20, no. 9, pp. 1501-1503, 2006.

[10] J. Zhen, H. Lu, X. Q. Wang, N. D. Vaziri, and X. J. Zhou, “Upregulation of endothelial and inducible nitric oxide synthase expression by reactive oxygen species," American Journal of Hypertension, vol. 21, no. 1, pp. 28-34, 2008.

[11] S. Park, W. Jung, S. Moon et al., "Chunghyuldan activates NOS mRNA expression and suppresses VCAM-1 mRNA expression in human endothelial cells," Canadian Journal of Physiology and Pharmacology, vol. 83, no. 12, pp. 1101-1108, 2005.

[12] I. C. W. Arts and P. C. H. Hollman, "Polyphenols and disease risk in epidemiologic studies," The American Journal of Clinical Nutrition, vol. 81, no. 1, supplement, pp. 317S-325S, 2005.

[13] M. Appeldoorn, D. Venema, T. Peters et al., "Some phenolic compounds increase the nitric oxide level in endothelial cells in vitro," Journal of Agricultural and Food Chemistry, vol. 57, no. 17, pp. 7693-7699, 2009.

[14] M. Atanassova and V. Bagdassarian, "Rutin content in plant products," Journal of the University of Chemical Technology and Metallurgy, vol. 44, no. 2, pp. 201-203, 2009. 
[15] A. Ugusman, Z. Zakaria, C. K. Hui, N. A. M. M. Nordin, and Z. A. Mahdy, "Flavonoids of Piper sarmentosum and its cytoprotective effects against oxidative stress," EXCLI Journal, vol. 11, pp. 705-714, 2012.

[16] R. Guo, P. Wei, and W. Liu, "Combined antioxidant effects of rutin and Vitamin C in Triton X-100 micelles," Journal of Pharmaceutical and Biomedical Analysis, vol. 43, no. 4, pp. 15801586, 2007.

[17] T. Kauss, D. Moynet, J. Rambert et al., "Rutoside decreases human macrophage-derived inflammatory mediators and improves clinical signs in adjuvant-induced arthritis," Arthritis Research and Therapy, vol. 10, no. 1, article R19, 2008.

[18] J. Sheu, G. Hsiao, P. Chou, M. Shen, and D. Chou, "Mechanisms involved in the antiplatelet activity of rutin, a glycoside of the flavonol quercetin, in human platelets," Journal of Agricultural and Food Chemistry, vol. 52, no. 14, pp. 4414-4418, 2004.

[19] S. K. Panchal, H. Poudyal, T. V. Arumugam, and L. Brown, "Rutin attenuates metabolic changes, nonalcoholic steatohepatitis, and cardiovascular remodeling in high-carbohydrate, high-fat diet-fed rats," The Journal of Nutrition, vol. 141, no. 6 , pp. 1062-1069, 2011.

[20] M. Ajay, A. H. Gilani, and M. R. Mustafa, "Effects of flavonoids on vascular smooth muscle of the isolated rat thoracic aorta," Life Sciences, vol. 74, no. 5, pp. 603-612, 2003.

[21] T. Rukachaisirikul, P. Siriwattanakit, K. Sukcharoenphol et al., "Chemical constituents and bioactivity of Piper sarmentosum," Journal of Ethnopharmacology, vol. 93, no. 2-3, pp. 173-176, 2004.

[22] A. Ugusman, Z. Zakaria, C. K. Hui, and N. A. M. M. Nordin, "Piper sarmentosum increases nitric oxide production in oxidative stress: A study on human umbilical vein endothelial cells," Clinics, vol. 65, no. 7, pp. 709-714, 2010.

[23] A. Ugusman, Z. Zakaria, C. K. Hui, and N. A. Megat Mohd Nordin, "Piper sarmentosum inhibits ICAM-1 and Nox4 gene expression in oxidative stress-induced human umbilical vein endothelial cells," BMC Complementary \& Alternative Medicine, vol. 11, no. 1, article 31, 2011.

[24] A. Hegde, M. Uttamchandani, S. M. Moochhala, and M. Bhatia, "Plasma cytokine profiles in Preprotachykinin-A knockout mice subjected to polymicrobial sepsis," Molecular Medicine, vol. 16, no. 1-2, pp. 45-52, 2010.

[25] I. Fleming and R. Busse, "Molecular mechanisms involved in the regulation of the endothelial nitric oxide synthase," American Journal of Physiology: Regulatory Integrative and Comparative Physiology, vol. 284, no. 1, pp. R1-R12, 2003.

[26] G. R. Drummond, H. Cai, M. E. Davis, S. Ramasamy, and D. G. Harrison, "Transcriptional and posttranscriptional regulation of endothelial nitric oxide synthase expression by hydrogen peroxide," Circulation Research, vol. 86, no. 3, pp. 347-354, 2000.

[27] L. J. Ignarro, R. E. Byrns, D. Sumi, F. de Nigris, and C. Napoli, "Pomegranate juice protects nitric oxide against oxidative destruction and enhances the biological actions of nitric oxide," Nitric Oxide, vol. 15, no. 2, pp. 93-102, 2006.

[28] G. Gong, Y. Qin, W. Huang, S. Zhou, X. Yang, and D. Li, "Rutin inhibits hydrogen peroxide-induced apoptosis through regulating reactive oxygen species mediated mitochondrial dysfunction pathway in human umbilical vein endothelial cells," European Journal of Pharmacology, vol. 628, no. 1-3, pp. 27-35, 2010.

[29] N. N. Danial and S. J. Korsmeyer, "Cell death: critical control points," Cell, vol. 116, no. 2, pp. 205-219, 2004.
[30] P. Kaur, M. Aschner, and T. Syversen, "Glutathione modulation influences methyl mercury induced neurotoxicity in primary cell cultures of neurons and astrocytes," NeuroToxicology, vol. 27, no. 4, pp. 492-500, 2006.

[31] H. Cai, "Hydrogen peroxide regulation of endothelial function: origins, mechanisms, and consequences," Cardiovascular Research, vol. 68, no. 1, pp. 26-36, 2005.

[32] M. S. Zadeh, J.-P. Kolb, D. Geromin et al., "Regulation of ICAM1/CD54 expression on human endothelial cells by hydrogen peroxide involves inducible NO synthase," Journal of Leukocyte Biology, vol. 67, no. 3, pp. 327-334, 2000.

[33] K. Kazłowska, T. Hsu, C.-C. Hou, W.-C. Yang, and G.-J. Tsai, "Anti-inflammatory properties of phenolic compounds and crude extract from Porphyra dentata," Journal of Ethnopharmacology, vol. 128, no. 1, pp. 123-130, 2010.

[34] A. Korkmaz and D. Kolankaya, "Inhibiting inducible nitric oxide synthase with rutin reduces renal ischemia/reperfusion injury," Canadian Journal of Surgery, vol. 56, no. 1, pp. 6-14, 2013.

[35] H. Li, T. Wallerath, and U. Förstermann, "Physiological mechanisms regulating the expression of endothelial-type NO synthase," Nitric Oxide, vol. 7, no. 2, pp. 132-147, 2002.

[36] S. K. Kostyk, S. Kourembanas, E. L. Wheeler et al., "Basic fibroblast growth factor increases nitric oxide synthase production in bovine endothelial cells," The American Journal of PhysiologyHeart and Circulatory Physiology, vol. 269, no. 5, pp. H1583H1589, 1995.

[37] J. Zheng, I. M. Bird, A. N. Melsaether, and R. R. Magness, "Activation of the mitogen-activated protein kinase cascade is necessary but not sufficient for basic fibroblast growth factor- and epidermal growth factor-stimulated expression of endothelial nitric oxide synthase in ovine fetoplacental artery endothelial cells," Endocrinology, vol. 140, no. 3, pp. 1399-1407, 1999.

[38] P. Cuevas, F. Carceller, S. Ortega, M. Zazo, I. Nieto, and G. Gimenez-Gallego, "Hypotensive activity of fibroblast growth factor," Science, vol. 254, no. 5035, pp. 1208-1210, 1991.

[39] S. Rosenblatt, K. Irikura, C. G. Caday, S. P. Finklestein, and M. A. Moskowitz, "Basic fibroblast growth factor dilates rat pial arterioles," Journal of Cerebral Blood Flow \& Metabolism, vol. 14, no. 1, pp. 70-74, 1994.

[40] P. Cuevas, M. García-Calvo, F. Carceller et al., "Correction of hypertension by normalization of endothelial levels of fibroblast growth factor and nitric oxide synthase in spontaneously hypertensive rats," Proceedings of the National Academy of Sciences of the United States of America, vol. 93, no. 21, pp. 11996-12001, 1996.

[41] L. Schweigerer, G. Neufeld, J. Friedman, J. A. Abraham, J. C. Fiddes, and D. Gospodarowicz, "Capillary endothelial cells express basic fibroblast growth factor, a mitogen that promotes their own growth," Nature, vol. 325, no. 6101, pp. 257-259, 1987.

[42] L. Colucci-D’Amato, C. Perrone-Capano, and U. di Porzio, "Chronic activation of ERK and neurodegenerative diseases," BioEssays, vol. 25, no. 11, pp. 1085-1095, 2003.

[43] C. J. Marshall, "Specificity of receptor tyrosine kinase signaling: transient versus sustained extracellular signal-regulated kinase activation," Cell, vol. 80, no. 2, pp. 179-185, 1995.

[44] D. T. Denhardt, "Signal-transducing protein phosphorylation cascades mediated by Ras/Rho proteins in the mammalian cell: the potential for multiplex signalling," Biochemical Journal, vol. 318, part 3, pp. 729-747, 1996.

[45] J. Blenis, "Signal transduction via the MAP kinases: proceed at your own RSK," Proceedings of the National Academy of Sciences 
of the United States of America, vol. 90, no. 13, pp. 5889-5892, 1993.

[46] T. Florio, S. Arena, A. Pattarozzi et al., "Basic fibroblast growth factor activates endothelial nitric-oxide synthase in CHOK1 cells via the activation of ceramide synthesis," Molecular Pharmacology, vol. 63, no. 2, pp. 297-310, 2003.

[47] I. Fleming and R. Busse, "Signal transduction of eNOS activation," Cardiovascular Research, vol. 43, no. 3, pp. 532-541, 1999.

[48] S. K. Nicholson, G. A. Tucker, and J. M. Brameld, "Physiological concentrations of dietary polyphenols regulate vascular endothelial cell expression of genes important in cardiovascular health," British Journal of Nutrition, vol. 103, no. 10, pp. 13981403, 2010.

[49] D. Bouïs, G. A. P. Hospers, C. Meijer, G. Molema, and N. H. Mulder, "Endothelium in vitro: a review of human vascular endothelial cell lines for blood vessel-related research," Angiogenesis, vol. 4, no. 2, pp. 91-102, 2001.

[50] C. A. Watson, L. Camera-Benson, R. Palmer-Crocker et al., "Variability among human umbilical vein endothelial cultures," Science, vol. 268, no. 5209, pp. 447-448, 1995. 

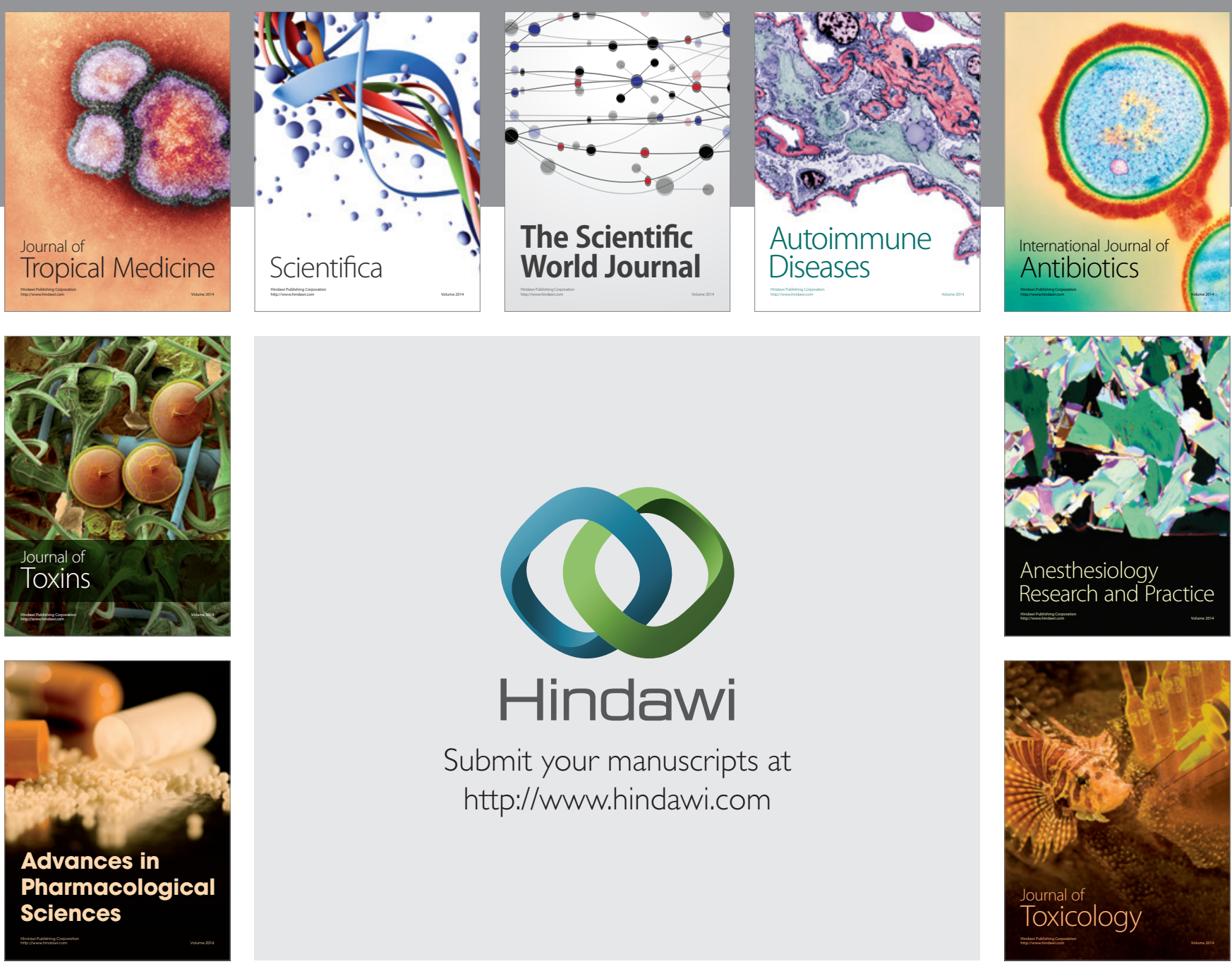

\section{Hindawi}

Submit your manuscripts at

http://www.hindawi.com
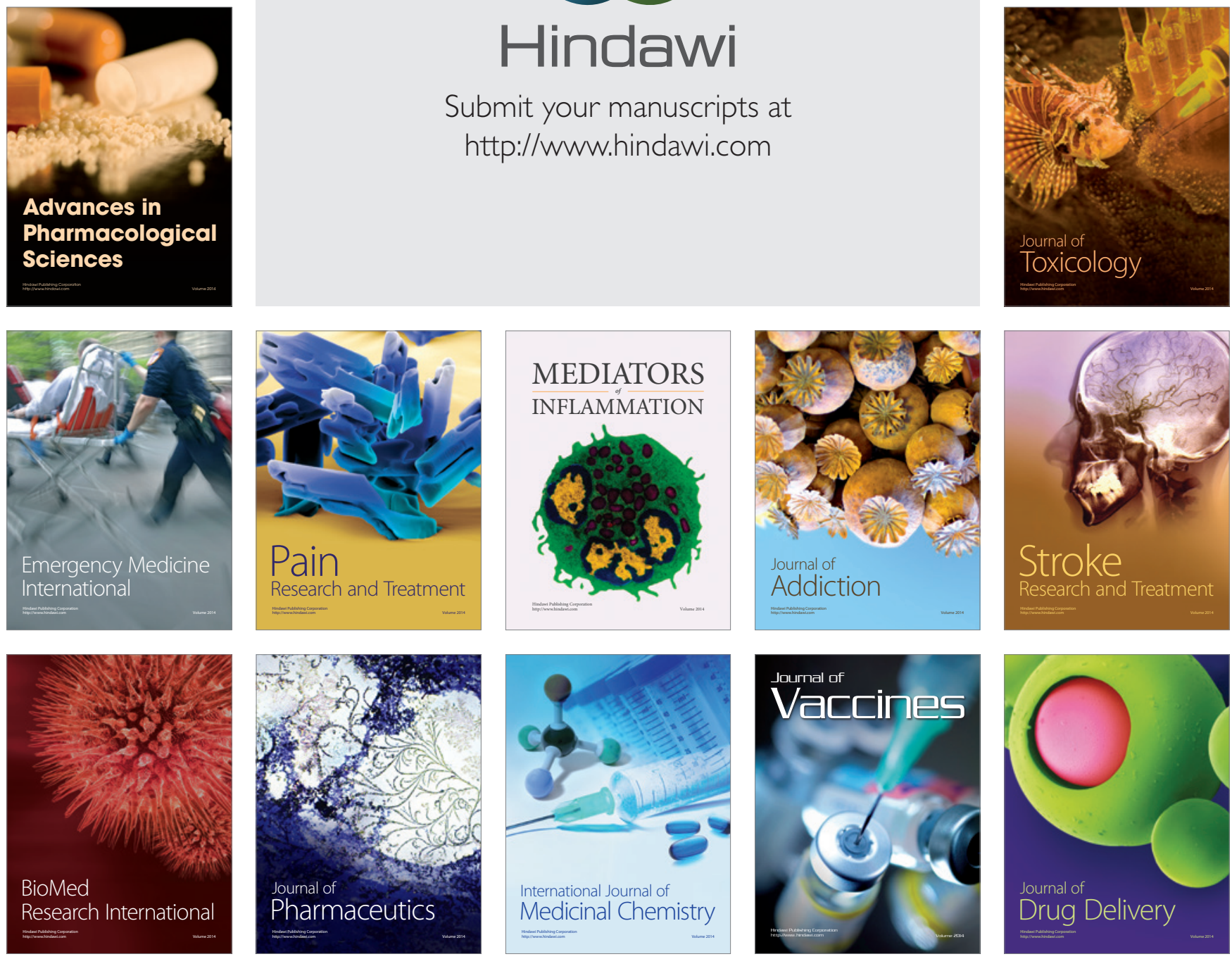